\title{
Differences between Cheeks and Dorsal Hands Skin Properties during Skiing in a Cold and Windy Environment
}

\author{
Sue Im Jang, Jiyei Choi, Jiyeon Han, Eun Joo Kim, Hae Kwang Lee* \\ AMORE PACIFIC Corporation/R \& D CENTER, Yongin, Korea \\ Email: sijang@amorepacific.com,jy_choi@amorepacific.com, sviviria@amorepacific.com, eon827@amorepacific.com, \\ ^haekwang@amorepacific.com
}

How to cite this paper: Jang, S.I., Choi, J., Han, J., Kim, E.J. and Lee, H.K. (2017) Differences between Cheeks and Dorsal Hands Skin Properties during Skiing in a Cold and Windy Environment. Journal of Cosmetics, Dermatological Sciences and Applications, 7, 27-33.

https://doi.org/10.4236/jcdsa.2017.71003

Received: January 18, 2017

Accepted: February 27, 2017

Published: March 2, 2017

Copyright $\odot 2017$ by authors and Scientific Research Publishing Inc. This work is licensed under the Creative Commons Attribution International License (CC BY 4.0).

http://creativecommons.org/licenses/by/4.0/

\begin{abstract}
Background/Purpose: The skin protects against external factors and this skin function can be affected by environmental conditions, including low temperature, low humidity, and high altitude. Therefore, it is important to study the relationship between the environment and the skin. The purpose of this study is to determine how the skin barrier functions change at low temperatures. Methods: This study was performed at a Korean ski resort on January 2015 and evaluated 10 subjects skin condition during skiing. Skin properties were examined at 2 sites (cheeks and dorsal hands) and four time points (indoor; baseline, outdoor; after first skiing and after second skiing, indoor; after taking a shower). Results: The skin hydration on the cheek decreased after the second skiing session and the erythema decreased only after the first skiing while this value on dorsal hand was not changed by skiing. The brightness and yellowness of cheek skin increased and redness decreased therefore, skin color became pale during skiing. The extensibility of cheeks and dorsal hands decreased after skiing. We found positive correlation between skin temperature and redness $\left(r^{2}=0.707, \mathrm{p}<0.000\right)$. Also the skin properties changed according to ambient temperature. The cheek skin temperature, erythema, redness and extensibility increased when people moved from outdoor to indoor while skin brightness and yellowness decreased. The skin hydration on both cheeks and dorsal hands and the skin properties except skin temperature of dorsal hands didn't change significantly. Conclusions: Low temperatures can affect human skin color so that the skin color becomes pale because capillary blood vessels shrink when skin is exposed to cold environment. The cheek skin tends to change easily than dorsal hand during ambient temperature change.
\end{abstract}

\section{Keywords}

Low Temperature, Environment, Skiing, Hydration, Skin Color, Elasticity, 
Skin Temperature, Skin Redness

\section{Introduction}

Aging arises from both intrinsic and extrinsic factors. The most commonly studied aspect of extrinsic aging is the exposure of skin to ultraviolet radiation which causes skin damage and erythema by creating reactive oxygen species and DNA damage [1]. However, various other extrinsic factors exist including smoking, alcohol consumption, ozone, climate, and geography; for example, changes in skin have been noted at extremely low humidity (relatively humidity [RH] $<1.5 \%$ ) [2] and high altitude (>2900 m) [3].

A positive relationship has been reported between skin temperature and ambient temperature [4], and many people who ski during winter are exposed to the certain circumstances. Furthermore, humans feel thermally neutral when their average skin temperature is $33.0^{\circ} \mathrm{C}$ throughout the whole body [5]. Under normal conditions, the skin maintains homeostasis and acts as a protective barrier although it is possible that these functions are weakened at low temperatures. Furthermore there are few studies regarding changes in skin properties due to cold temperatures while the effect of cold temperatures on skin temperature is well studied. Therefore, the purpose of this study was to determine how the skin's barrier function changes at low temperatures, such as at a ski resort.

\section{Materials and Methods}

\subsection{Study Design}

This study was performed at a Korean ski resort on January 2015 and included 10 participants who were 20 - 25 years old $(24.3 \pm 1.6$ years, 6 men and 4 women). All the subjects voluntarily chose to participate and provide their written informed consent. Five parameters (hydration, erythema, skin color, extensibility and skin temperature) were measured at two sites (cheeks and dorsal hands).

1) Baseline: After washing their faces and hands, participants were stayed for $20 \mathrm{~min}$ in the resort room at temperature of $22.66^{\circ} \mathrm{C} \pm 3.04^{\circ} \mathrm{C}$ and $\mathrm{RH}$ of $27.79 \%$ $\pm 2.13 \%$. 2) After first skiing: Participants skied for $3 \mathrm{~h}(2: 30$ - 5:30 PM) at temperature of $0.60^{\circ} \mathrm{C} \pm 0.14^{\circ} \mathrm{C}, \mathrm{RH}$ of $40.55 \% \pm 0.78 \%$, and wind speed of $4.8 \mathrm{~m} / \mathrm{s}$; their skin properties were measured outdoors. 3) After second skiing: Participants skied for $2 \mathrm{~h}(8: 00-10: 00 \mathrm{PM})$ at temperature of $-3.70^{\circ} \mathrm{C} \pm 0.54^{\circ} \mathrm{C}, \mathrm{RH}$ of $42.48 \% \pm 0.67 \%$, and wind speed of $4.8 \mathrm{~m} / \mathrm{s}$; their skin properties were measured outdoors. 4) After taking a shower: Participants showered using the same body wash product and relaxed in the resort room at temperature of $21.01^{\circ} \mathrm{C} \pm 6.06^{\circ} \mathrm{C}$ and $\mathrm{RH}$ of $27.99 \% \pm 4.50 \%$ for $20 \mathrm{~min}$.

\subsection{Measuring Hydration, Erythema and Elasticity}

Skin hydration, erythema and extensibility were measured using the Corneome- 
$\operatorname{ter}^{\circledR}$, Mexameter ${ }^{\circledR}$ and Cutometer ${ }^{\circledR}$ MPA580 devices (C + K, Köln, Germany), respectively. The Corneometer performs a capacitance measurement while the Cutometer generates negative pressure ( $450 \mathrm{mbar}$ ) using a $2-\mathrm{mm}$ probe. The Cutometer was applied to the skin for $2 \mathrm{~s}$ of suction and $2 \mathrm{~s}$ of relaxation, with three repetitions for each measuring cycle. Skin extensibility was measured and reported as either R0. All data were analyzed using the average of three repetitions, and the percentage change was calculated using the formula: ([Baseline measurement point $] /$ Baseline) $\times 100$.

\subsection{Measuring Skin Colors}

The skin colors were measured via spectrophotometry (CM2600d; KONICA MINOLTA SENSING, Tokyo, Japan). This technique provides a quantitative measurement of the reflection properties of the skin, which are represented by brightness $\left(\mathrm{L}^{*}\right)$, redness $\left(\mathrm{a}^{*}\right)$ and yellowness $\left(\mathrm{b}^{*}\right)$.

\subsection{Measuring Skin Temperature}

The skin temperatures $\left(T_{s k}\right)$ were measured using a noncontact thermometer (Rayger ST Pro; Raytek, Berlin, Germany). This instrument measures the amount of infrared energy that is emitted by the target object.

\subsection{Statistical Analysis}

All statistical analyses were performed using SPSS software (SPSS Inc., Chicago, IL, USA), and the differences were considered statistically significant at a p-value of $<0.05$. The parametric test, repeated measures analysis of variance test, and paired T-test were used, appropriately.

\section{Results}

\subsection{Changes in the Skin Properties}

The hydration was higher on cheek than dorsal hand at baseline. The water content level of cheek and dorsal hand didn't decrease after 2 times of skiing but it decreased on both sites after shower. The slope of hydration on cheek changed after second skiing, although the dorsal hand's changed after shower (Figure 1 (a)). The erythema on cheek decreased after the first skiing session while dorsal hand skin decreased after shower (Figure 1(b)). The skin brightness on cheek increased, and redness decreased, after first skiing (Figure 1(c), Figure 1(d)). Skin yellowness on cheek increased after first skiing and it did not recover (Figure 1(e)). These changes contributed to a pale color of the skin. However the brightness and yellowness on dorsal hand were not changed. The extensibility decreased after first skiing on both cheeks skin and dorsal hands skin (Figure 1(f)), which indicates that the skin became stiffened [6]. The extensibility of dorsal hand skin shown fast decline slope after skiing that means dorsal hand skin is easy to stretch as well as easy to be stiff. 


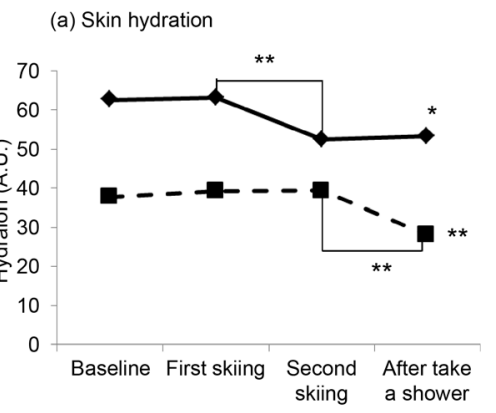

(c) Skin brightness

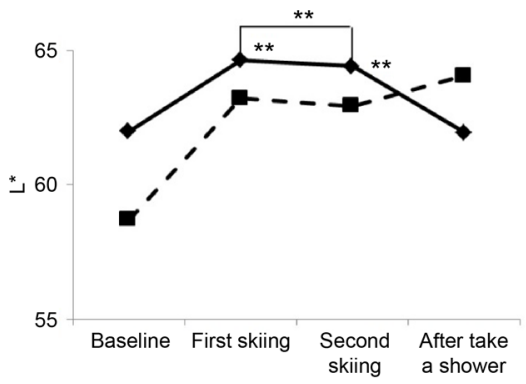

(e) Skin yellowness

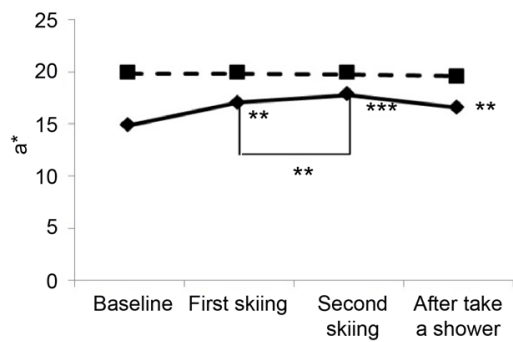

(b) Erythema

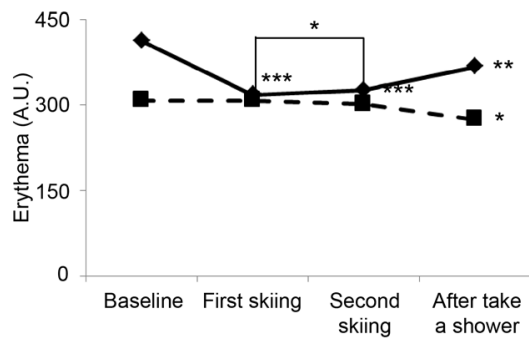

(d) Skin redness

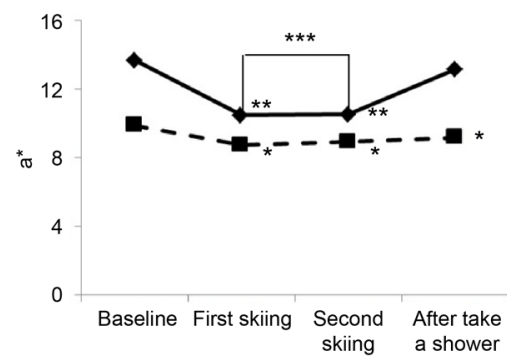

(f) Skin extensibility

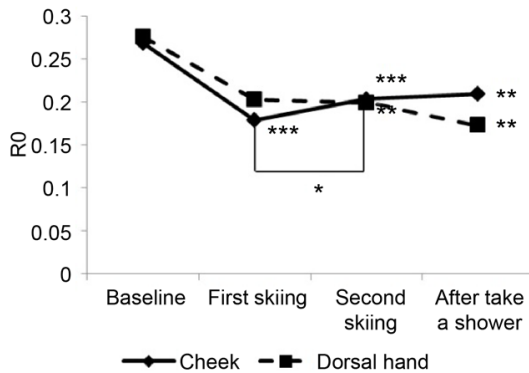

Figure 1. The cheeks and dorsal hands skin properties at each time points. Hydration (a), Erythema (b), Skin brightness (c), Redness (d), Yellowness (e) and R0 (skin extensibility) (f) (RM-ANOVA, $\left.{ }^{\star} \mathrm{p}<0.05,{ }^{* *} \mathrm{p}<0.01,{ }^{* *} \mathrm{p}<0.001\right)$.

\subsection{The Pearson's Correlation Coefficient between Skin Temperature and Skin Properties}

We determined relationship between skin temperature and skin properties. The erythema, redness and extensibility on cheek were increased with temperature elevation but the brightness decreased depending on the temperature. Above all, redness $\left(\mathrm{a}^{\star}\right)$ on cheek had strong positive correlation with the skin temperature $\left(\mathrm{r}^{2}=0.707, \mathrm{p}<0.001\right)$. The skin on dorsal hand, however, showed positive correlation with skin redness only (Table 1).

\subsection{Changes of Skin Properties from Outside to Inside}

The subjects stayed about 3 hour at outdoor $\left(-3^{\circ} \mathrm{C} \sim 0^{\circ} \mathrm{C}\right.$, $\left.\mathrm{RH} 40 \% \sim 43 \%\right)$ and then, they moved into indoor $\left(21^{\circ} \mathrm{C} \sim 24^{\circ} \mathrm{C}\right.$, RH $\left.28 \% \sim 30 \%\right)$. The skin temperature statistically increased when subjects moved from outdoor to indoor (Figure 2(a)). However, the skin hydration level didn't change along with environmental changes (Figure 2(b)). The erythema, redness, and extensibility on 
Table 1. Pearson's correlation between skin temperature and skin properties.

\begin{tabular}{ccccccc}
\hline & Hydration & Erythema & $\mathrm{L}^{*}$ & $\mathrm{a}^{*}$ & $\mathrm{~b}^{*}$ & $\mathrm{R} 0$ \\
\hline Cheeks & -0.006 & $\mathbf{0 . 5 5 2 * * *}$ & $-\mathbf{0 . 5 3 3 ^ { * * * }}$ & $\mathbf{0 . 7 0 7 ^ { * * * }}$ & -0.292 & $\mathbf{0 . 5 5 2 ^ { * * * }}$ \\
Dorsal hand & -0.192 & -0.135 & -0.031 & $\mathbf{0 . 3 2 7 ^ { * }}$ & 0.040 & 0.065 \\
\hline${ }^{*} \mathrm{p}<0.05,{ }^{* *} \mathrm{p}<0.01,{ }^{* * *} \mathrm{p}<0.001$. & & & &
\end{tabular}

(a) Skin temperature

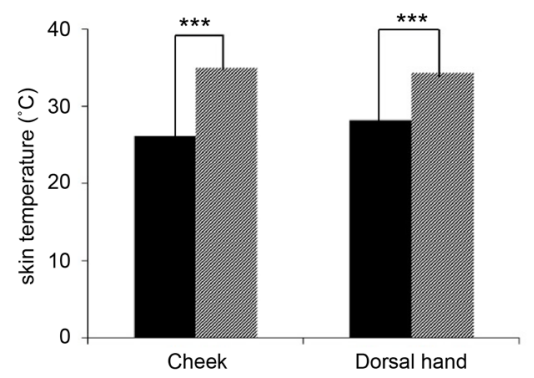

(c) Erythema

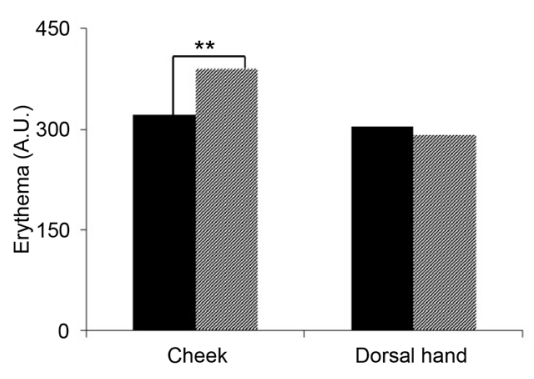

(e) Skin redness

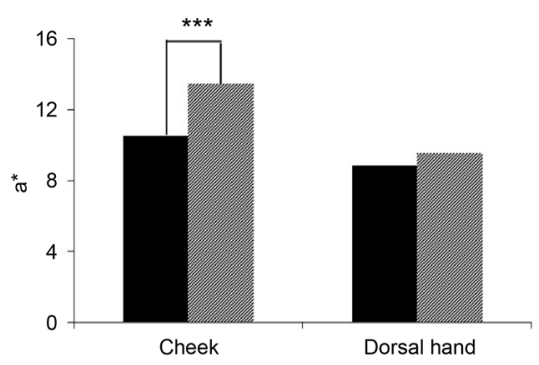

(g) Skin extensibility

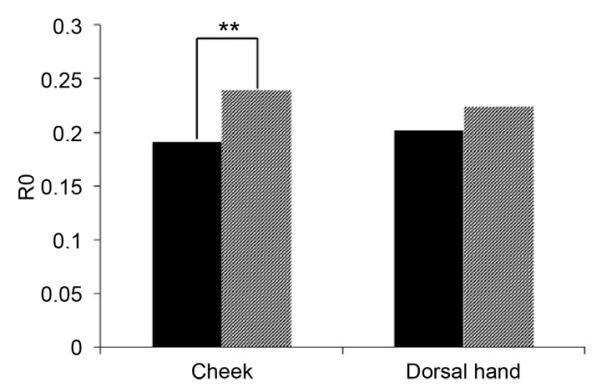

Figure 2. The skin properties depending on sudden changes of environment. Skin temperature (a), Hydration (b), Erythema (c), Skin brightness (d), Redness (e), Yellowness (f) and R0 (skin extensibility) (f) (Paired T-test, ${ }^{*} \mathrm{p}<0.05,{ }^{* *} \mathrm{p}<0.01$, ${ }^{* * *} \mathrm{p}<0.001$ ). 
cheek skin increased but brightness and yellowness decreased with the sudden change from outdoor to indoor (Figures 2(c)-2(g)). The skin properties on dorsal hand were not changed except skin temperature (Figures 2(a)-2(g)).

\section{Discussion}

Many recent studies have examined the effects of environmental factors on the skin such as decreased skin hydration due to the low RH within an airplane [7]. Other studies have evaluated the biophysical changes that are occurred during the different seasons [8]. This study aimed to expand our understanding of the effects of environmental factors on skin barrier function, especially at low temperatures. For example, we observed that the extensibility of cheek skin decreased and skin color began to change pale after the first skiing session. In addition, the skin hydration decreased after second skiing session.

Although redness and extensibility on dorsal hand changed by skiing, the extensibility on dorsal hand was higher than cheek because the cheek skin is thicker than the dorsal hand [9].

The skin redness has a positive correlation with the skin temperature because capillary blood vessels of the skin shrink and blood flow decreases when skin is exposed to cold environment [10]. There are many researches about low ambient temperature and low skin trans-epidermal water loss (TEWL) [11] [12] [13] but there are few researches that show the relationship between skin temperature and skin redness. Therefore this result shows that the skin redness can be a new parameter in research related to the temperature change.

People often feel their face turn red when move from the cold outside environment into a warm indoor place. This research confirmed that face skin changes more easily than hand skin and there's a report that the distribution of perfusion of cheek is higher than dorsal hand which is defined by two-dimensional laser doppler flow [14].

In previous studies, they exposed skin to a low temperature circumstances with repeated short-time period and this has shown the acceleration of recovery speed of dermal wound healing through strengthened immune-related process [15]. Therefore, we sought to find the effect of long-time exposure at low temperature on skin and the major result was change in skin color. We studied skin properties over time at a ski resort, which provided an accurate test for skin exposure during the winter. In summary, our findings indicate that low temperatures can affect human skin's properties and it is important to take care of skin that is exposed to low temperatures. As further studies, we will convey research to evaluate the effects of other different environmental conditions on the skin's function.

\section{References}

[1] Ichihashi, M., Ueda, M., Budiyanto, A., et al. (2003) UV-Induced Skin Damage. Toxicology, 189, 21-39. https://doi.org/10.1016/S0300-483X(03)00150-1

[2] Chou, T.C., Lin, K.H., Wang, S.M., et al. (2005) Transepidermal Water Loss and Skin Capacitance Alterations among Workers in an Ultra-Low Humidity Environ- 
ment. Archives of Dermatological Research, 296, 489-495.

https://doi.org/10.1007/s00403-005-0541-4

[3] Mazzarello, V., Cametti, M., Leone, G., et al. (2001) Analysis of the Microtopography of the Skin by Silicone Replicas after Repeated Exposure to Actinic Radiation at High Altitudes. Journal of the European Academy of Dermatology and Venereolo$g y, 15,224-228$. https://doi.org/10.1046/j.1468-3083.2001.00248.x

[4] Cravello, B. and Ferri, A. (2008) Relationships between Skin Properties and Environmental Parameters. Skin Research and Technology, 14, 180-186.

https://doi.org/10.1111/j.1600-0846.2007.00275.x

[5] Wang, Z., He, Y., Hou, J., et al. (2013) Human Skin Temperature and Thermal Responses in Asymmetrical Cold Radiation Environments. Building and Environment, 67, 217-223. https://doi.org/10.1016/j.buildenv.2013.05.020

[6] Serup, J. and Northeved, A. (1985) Skin Elasticity in Psoriasis. In Vivo Measurement of Tensile Distensibility, Hysteresis and Resilient Distension with a New Method. Comparison with Skin Thickness as Measured with High-Frequency Ultrasound. Journal of Dermatology, 12, 318-324.

https://doi.org/10.1111/j.1346-8138.1985.tb02848.x

[7] Guéhenneux, S., Gardinier, S., Morizot, F., Le Fur, I. and Tschachler, E. (2012) Skin Surface Hydration Decreases Rapidly during Long Distance Flights. Skin Research and Technology, 18, 238-240. https://doi.org/10.1111/j.1600-0846.2011.00560.x

[8] Black, D., Del Pozo, A., Lagarde, J.M. and Gall, Y. (2000) Seasonal Variability in the Biophysical Properties of Stratum Corneum from Different Anatomical Sites. Skin Research and Technology, 6, 70-76. https://doi.org/10.1034/j.1600-0846.2000.006002070.x

[9] Nedelec, B., Forget, N.J., Hurtubise, T., et al. (2016) Skin Characteristics: Normative data for Elasticity, Erythema, Melanin, and Thickness at 16 Differentanatomical Locations. Skin Research and Technology, 22, 263-275. https://doi.org/10.1111/srt.12256

[10] Halkier-Sorensen, L. and Thestrup-Pedersen, K. (1991) Skin Physiological Changes in Employees in the Fish Processing Industry Immediately Following Work. A Field Study. Contact Dermatitis, 25, 19-24. https://doi.org/10.1111/j.1600-0536.1991.tb01767.x

[11] Grice, K., Sattar, H., Sharratt, M. and Baker, H. (1971) Skin Temperature and Transepidermal Water Loss. Journal of Investigative Dermatology, 57, 108-110. https://doi.org/10.1111/1523-1747.ep12349617

[12] Mathias, C.G.T., Wilson, D.M. and Maibach, H.I. (1981) Transepidermal Water Loss as Afunction of Skin Surface Temperature. Journal of Investigative Dermatology, 77, 219-220. https://doi.org/10.1111/1523-1747.ep12479939

[13] Halkier-Sorensen, L. and Thestrup-Pedersen, K. (1991) The Relationship between Skinsurface Temperature, Transepidermal Water Loss and Electrical Capacitance among Workers in the Fish Processing Industry: Comparison with Other Occupations. A Field Study. Contact Dermatitis, 24, 345-355. https://doi.org/10.1111/j.1600-0536.1991.tb01749.x

[14] Stucker, M., Steinberg, J., Memmel, U., Avermaete, A., Hoffmann, K. and Altmeyer, P. (2001) Differences in the Two-Dimensionally Measured Laser Doppler Flow at Different Skin Localisations. Skin Pharmacology and Applied, 14, 44-51. https://doi.org/10.1159/000056333

[15] Graham, J.E., Song, S. and Engeland, C.G. (2012) Acute Pain Speeds Skin Barrier Recovery in Healthy Men and Women. Journal of Psychosomatic Research, 73, 452458. https://doi.org/10.1016/j.jpsychores.2012.07.011 
Submit or recommend next manuscript to SCIRP and we will provide best service for you:

Accepting pre-submission inquiries through Email, Facebook, LinkedIn, Twitter, etc. A wide selection of journals (inclusive of 9 subjects, more than 200 journals)

Providing 24-hour high-quality service

User-friendly online submission system

Fair and swift peer-review system

Efficient typesetting and proofreading procedure

Display of the result of downloads and visits, as well as the number of cited articles Maximum dissemination of your research work

Submit your manuscript at: http://papersubmission.scirp.org/

Or contact jcdsa@scirp.org 